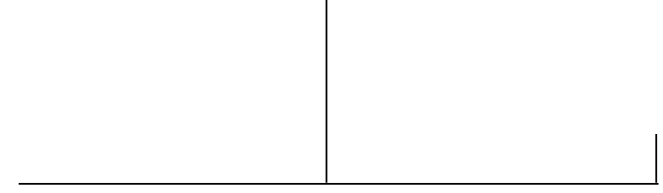

Rev. Latinoam. Psicopat. Fund., São Paulo, v. 12, n. 1, p. 167-194, março 2009

\title{
As formas de manifestação da insanidade*
}

Emil Kraepelin

\begin{abstract}
Com muita frequência nos últimos tempos manifestou-se a opinião de que a pesquisa em psiquiatria clínica chegou de certa forma a um ponto de estagnação. ${ }^{1} \mathrm{O}$ método até hoje empregado para delimitar as várias formas de doença - considerando as causas, os sintomas, a evolução e o desenlace assim como a causa mortis - estaria desgastado e não seria mais suficiente: novos caminhos, portanto, deveriam ser buscados. Não podemos deixar de dar certa razão a afirmações como essa. Quando pela primeira vez se começou a examinar tecidos sobre lâminas ao microscópio, a cada dia se faziam novas descobertas; hoje só é possível conseguir avanços significativos com a utilização de recursos técnicos muitíssimo sofisticados. Da mesma maneira, não é sem grande esforço que conseguimos ampliar nossos conhecimentos sobre as várias formas de doença, agora que as questões mais óbvias parecem estar mais ou menos esclarecidas. Quanto mais nos aprofundamos no assunto, maiores se tornam as dificuldades e tão
\end{abstract}

* Tradução do alemão de Monica Niemeyer. Agradecemos a colaboração do Prof. Dr. German E. Berrios, que nos cedeu o original.

1. Z.f.d.g.Neur. u. Psych. 0. LXII. = Zeitschrift für die gesamte Neurologie und Psychiatrie 0. LXII. 
mais completo deve ser o arsenal de apoio com o qual trabalhamos. Apesar de tudo isso, nossos êxitos tornaram-se mais modestos, mas teremos que nos contentar com esse ritmo de desenvolvimento, que corresponde plenamente às experiências gerais da pesquisa científica.

Nestas circunstâncias, certamente é válido perguntar-se se não existem novas metas e caminhos que descortinem perspectivas mais promissoras para o trabalho clínico. É natural que os olhares se voltem da atividade puramente ordenadora de classificação ou de agrupamento das formas de doença para a tarefa indubitavelmente mais elevada e gratificante de conseguir uma compreensão sobre a essência e as conexões internas dos processos patológicos. Queremos não só conhecer a desconcertante multiplicidade das perturbações psíquicas em suas manifestações externas, mas também conseguir compreendê-las como resultantes de determinados pressupostos, descobrindo as leis que regem o seu surgimento.

Ninguém pretenderá negar que a solução de tarefas desse porte seja um grande desafio e mereça uma dedicação profunda. A dificuldade maior, no entanto, reside em encontrar caminhos que conduzam a essa meta com segurança. No agrupar das formas de doença, já temos uma diretriz mais ou menos confiável no pré-requisito de que todos os casos reunidos em uma unidade clínica apresentem analogias entre si no que se refere aos seus aspectos essenciais; os fatos observados na clínica fornecem as bases para as nossas decisões. No entanto, que caminhos deveremos seguir para nos inteirarmos da história inerente ao surgimento, sobre a "construção" de determinada doença - e que garantia temos de que os conhecimentos assim obtidos correspondem à realidade?

Adequando-nos ao raciocínio que descrevemos no início, deixaremos totalmente de lado as pretensões de pesquisar as bases físicas das doenças mentais nas discussões que se seguem. Nós nos limitaremos à questão de até onde - e com que ferramentas clínicas - é possível avançar para alcançar uma melhor compreensão das formas de manifestação da insanidade. A extraordinária variedade nas formas de apresentação dos quadros patológicos que correspondem ao mesmo sofrimento de base já indica, de saída, que as condições para o seu surgimento devem ser muito complexas. Também quando danos exteriores totalmente evidentes - tais como um ferimento na cabeça ou os efeitos de uma substância tóxica - são os responsáveis pela produção de um quadro patológico, estes danos incidem sobre um órgão que tem por trás de si características pessoais infinitamente ricas e de ordem histórico-hereditária. As disposições gerais do tecido nervoso, o substrato herdado das vivências de inúmeras gerações e, finalmente, os destinos individuais de cada paciente atuam juntos para amplamente influenciar o quadro clínico provocado por determinada causa - e para imprimir-lhe, enfim, uma marca totalmente personalizada. Todas estas pré-condições são 
especialmente decisivas naquelas formas do adoecer que surgem sem o concurso de fatores danosos externos, mas simplesmente das circunstâncias atinentes à personalidade em questão.

Considerações como essas sugerem que, na realidade, deveríamos atribuir às causas externas da insanidade uma influência genérica e apenas indicativa de uma direção na configuração do quadro patológico, enquanto os traços idiossincráticos resultam das particularidades do paciente. De fato, parece sem sentido supor que a meta-sífilis seja responsável por provocar no paciente a fantasia da posse de uma fortuna, de automóveis ou de casas no campo - ou, então, que a cocaína seja responsável por provocar nele a percepção alucinatória de ácaros ou piolhos etc. São os desejos do paciente que se manifestam nos delírios de grandeza referidos, enquanto as alucinações mencionadas recebem seu conteúdo idiossincrático somente depois do processamento, através das emoções, das perturbações visuais e sensoriais causadas pela cocaína. O que os danos exteriores causam, concentra-se principalmente na destruição, na paralisia, na excitação ou na inibição de partes do cérebro, mais expandidas ou mais circunscritas. O déficit, a insuficiência, o dificultar ou o facilitar deste ou daquele trabalho psíquico, as manifestações de irritação e os estados de excitação ou de estupor - eventualmente acompanhados de alterações de humor de coloridos diversos - são as consequências mais imediatas. No preenchimento desses contornos gerais, toda a gama de possibilidades origina-se das condições prévias relativas à influência daquilo que faz adoecer na personalidade do paciente.

Se as considerações acima são ao menos aproximadamente corretas, então teremos que procurar a chave para a compreensão das manifestações da doença principalmente nas singularidades gerais e específicas das pessoas em processo de adoecimento. A expectativa do indivíduo - influenciada pela situação real ou fantasiada, bem como pelas vivências pessoais anteriores - terá um papel decisivo no conteúdo das alucinações e das ilusões. Prejuízos de memória estendem--se em primeira linha àqueles traços de memória pouco exercitados, distantes do horizonte pessoal e de conotação afetiva desagradável, muitas vezes sujeitos a intensa repressão e transformação. A alucinação certamente se encontra submetida ao domínio das necessidades afetivas e constitui-se na expressão de temores genéricos e pessoais, de desejos e de expectativas. No paciente, o pensar em sua íntegra e a maneira particular de trabalhar as próprias vivências são afetados em larga medida por essas mesmas influências; e dependem também da constituição pessoal, da maneira como o indivíduo foi educado e, particularmente, das idiossincrasias na forma de pensar, condensadas na linguagem.

As moções de cunho afetivo surgidas na doença movimentam-se essencialmente nas trilhas desenhadas previamente pelas condições de vida de um indiví- 
duo. No entanto, é correto supor que certos estados de humor possam ser ocasionados diretamente por influências danosas: as intoxicações por álcool, cocaína, ópio, haxixe são exemplos disso. Mas, mesmo os efeitos clínicos de tais estados de humor, suas formas de expressão, sua influência sobre a percepção, o pensar e o agir, são totalmente dependentes das pré-condições existentes no sujeito. O mesmo vale para as expressões da vontade. Substâncias tóxicas podem paralisá-la ou excitá-la e processos patológicos podem suprimi-la completamente, mas - quaisquer que sejam as circunstâncias - a forma de expressão das ações e dos movimentos é determinada por disposições preexistentes, que se desenvolveram como ferramentas de nossa vontade. Os movimentos expressivos e as ações do querer aos quais, na verdade, devemos todos os nossos conhecimentos acerca dos processos anímicos de terceiros - talvez sejam especialmente adequados para tirarmos conclusões sobre as condições internas do surgimento dos quadros clínicos patológicos.

Existem dois caminhos principais para se obter uma compreensão mais aprofundada das manifestações das doenças. Um deles é pela "empatia" - aquele poético sentimento que nos coloca em sintonia com os processos anímicos que estão ocorrendo no outro. Ao procurarmos nos colocar em seu lugar através dos sentimentos, conseguimos entrar em contato com as raízes das causas de sua doença; conseguimos conhecer a história do desenvolvimento de suas alucinações e, eventualmente, conseguimos também identificar a "mola propulsora" oculta - e eventualmente longínqua - responsável por suas estranhas atitudes. É conhecida a afirmação da psicanálise de que ela teria conseguido grandes avanços nesse terreno e, se nela acreditássemos, não teria apenas sido descoberta a origem psíquica das diferentes "neuroses", mas também os processos emocionais dos esquizofrênicos, frequentemente tão incompreensíveis, teriam recebido uma surpreendente luz por essa via. Tampouco faltaram outras experiências, realizadas por meio de um cuidadoso aprofundamento na história prévia da patologia, com o intuito de encontrar os fios condutores determinantes de seu surgimento.

É evidente que experimentos desta ordem só podem levar a um resultado mais ou menos satisfatório nos casos em que a conexão psíquica entre as manifestações sadias e as patológicas não foi interrompida por ataques violentos. Pois é especialmente aqui que entram em questão aqueles desenvolvimentos anormais, nos quais estímulos vitais - corriqueiros ou excepcionais - são trabalhados de forma patológica em decorrência de uma insuficiência qualquer na personalidade psíquica. Com exceção dos diversos tipos de descarrilamento dos psicopatas, estão especialmente acessíveis a essa maneira de enxergar o assunto os transtornos oriundos de causas emocionais e, com certeza, também as alucinações dos paranoicos, uma vez que podemos encontrar as raízes dessa espécie de sofrimen- 
to, bem como dos processos psíquicos nele envolvidos, em nosso próprio interior - ao menos em forma de alusão. Tenho dúvidas se este caminho pode nos conduzir a conclusões proveitosas também no caso de a evolução da doença ter sido influenciada concomitantemente por eventos exteriores aos processos psíquicos. Este é o caso - não só nas formas de insanidade causada por fatores externos, mas também no extenso grupo das perturbações psíquicas, cujas condições de surgimento nós visualizamos - com maior ou menor propriedade - nas mudanças corporais internas. As conexões compreensíveis do acontecer psíquico podem, assim, ser adiadas ou interrompidas de maneira tão eficaz que fica muito difícil seguir o seu rastro com os meios auxiliares que estão ao nosso alcance.

Não devemos de modo algum procurar negar que cada tentativa nossa de compreender a vida psíquica de um terceiro em nosso próprio mecanismo está ligada a muitíssimas fontes de engano. Este já é o caso quando se trata de pessoas saudáveis, mas alcança um grau ainda mais elevado quando se trata de personalidades doentias. A "empatia" é um procedimento bastante inseguro que, no entanto, é indispensável para a aproximação entre os seres humanos e para a criação poética; mas, como meio auxiliar de pesquisa, pode levar aos maiores enganos. Uma vez que a empatia é influenciada em larga medida pelos próprios preconceitos e necessidades do indivíduo, ela pode fornecer um significativo montante de certeza óbvia. E isto é preocupante - principalmente porque não possuímos um parâmetro para a confiabilidade dessa impressão de certeza. Os construtos aventureiros dos psicanalistas - que se apresentam em toda parte com a reivindicação de forçosa validade - mostram-nos de maneira penetrante os perigos de uma forma de apreciação cuja exatidão não pode ser comprovada por verificações em outra parte.

Na realidade, parece haver um parâmetro útil que poderia nos proteger de aberrações dessa espécie - e este é constituído pelo testemunho dos próprios pacientes sobre suas vivências internas. Este procedimento parece extremamente sedutor e, sem dúvida, também apropriado para oferecer importantes esclarecimentos. No entanto, infelizmente não oferece uma proteção eficaz contra o autoengano. Precisamos apenas nos lembrar de que muitas das quimeras psicanalíticas foram justamente derivadas das afirmações dos pacientes. Com exceção da interpretação mais ou menos arbitrária por parte do observador, as importantíssimas fontes de engano do julgamento individual desempenham aqui um interessante papel. O êxtase, por exemplo, é um transtorno psíquico relativamente simples e bastante conhecido. Mesmo assim, é muito surpreendente constatar como são errôneas e cheias de contradições as opiniões dos observadores - mesmo daqueles que são cientistas - acerca das mudanças que ocorrem nos estados psíquicos do indivíduo durante o êxtase, antes de suas características e de seu alcance have- 
rem sido confirmados por experimentos seriamente conduzidos. Aqueles que se ocupam dessa espécie de vivência pouco confiarão nas informações fornecidas pelos doentes mentais sobre os processos que neles ocorrem, bem como sobre suas conexões internas. Precisamos ter o maior cuidado possível, uma vez que sabemos que a percepção de si mesmo, a memória e o julgamento de nossos pacientes costumam ser turvados por uma série de processos enganosos que, nos indivíduos saudáveis, no máximo estão presentes sob a forma de alusões. Para citar um exemplo bem corriqueiro, quero lembrá-los das explicações comuns em pacientes melancólicos de que eles adoeceram apenas por causa deste ou daquele fracasso, ou por causa de uma mudança, ou que eles só estão preocupados com uma questão de ordem econômica, ou que apenas adoeceram de saudade por terem sido separados de seus entes queridos e que, na verdade, eles não estão doentes, mas somente fingindo. Depois da cura, temos a oportunidade de acompanhar a correção dessas concepções errôneas. Mas quem poderá dizer a quantas conclusões enganosas estamos expostos, se tomarmos como verdadeiras as informações dos doentes cuja veracidade não é possível comprovar?

Certamente faremos um esforço para tirar conclusões a partir dessas informações. Ao mesmo tempo, porém, estaremos atentos na busca de outros caminhos que possam nos dar uma visão mais aprofundada do histórico do surgimento das manifestações patológicas. Seria especialmente importante se, dessa forma, conseguíssemos obter esclarecimentos não só sobre os encadeamentos de ordem psíquica, mas também sobre as interdependências entre os quadros patológicos de toda a história pregressa do indivíduo. Birnbaum com razão chamou atenção para o fato de que a forma de expressão das manifestações clínicas - com exceção da causa determinante da doença "patogenética" - é em larga medida influenciada pelas particularidades inatas e herdadas do paciente, bem como por toda espécie de influências passageiras ou duradouras. Ou seja, por todas as circunstâncias "patoplásticas" que, de alguma maneira, têm a capacidade de influenciar nos estados físicos e psíquicos. Pois é justamente essa relação que explica a grande variedade dos quadros patológicos provocados por esses mesmos danos. É por isto que observamos uma ampla concordância nos transtornos que são provocados por fatores patológicos inequívocos e fortemente atuantes como, por exemplo, os estados de êxtase provocados pelo alcoolismo. No entanto, quanto mais a evolução da patologia faz vir à tona as particularidades do paciente, tanto mais variadas se tornam as manifestações clínicas.

Os meios auxiliares para conseguirmos penetrar mais a fundo na relação de dependência entre as manifestações patológicas e as condições prévias apresentadas pelo doente nos são oferecidos pela psiquiatria comparada. Pela contraposição de grandes séries de observações é possível, inicialmente, pesquisar até onde as 
características gerais da pessoa, o sexo, a fase da vida e a etnia influenciam a forma de apresentação dos quadros patológicos; pode-se investigar, de modo similar, o significado da profissão, do clima, das circunstâncias de vida gerais e pessoais que se refletem no colorido especial das formas de manifestação clínicas. Contudo, o mais importante nesta relação é descobrir o papel decisivo que cabe àquilo que é constitucional no próprio sujeito, principalmente as influências da hereditariedade. Aqui, o pressuposto geral é o da contraposição entre formas semelhantes de patologias produzidas pelas mesmas causas, uma vez que se trata de esclarecer justamente a influência moldadora das circunstâncias acima descritas sobre os estados patológicos provenientes de uma mesma fonte. Disso resulta que a demarcação dos processos patológicos deve vir antes de todos os exames psiquiátrico-comparativos - e também no futuro deve constituir a base da qual necessariamente deverão partir os esforços para se chegar a uma compreensão da arquitetura interna dos transtornos mentais. Toda tentativa de trabalhar questões como essa - tomando por base material de observação composto de maneira irregular - necessariamente fracassará, em função da ambiguidade dos resultados e, especialmente, da impossibilidade de se conseguir manter as influências causais longe das influências formadoras.

Justamente essa dependência do esclarecimento das nossas constatações clínicas é a razão pela qual a psiquiatria comparada é uma ciência extraordinariamente jovem, ainda não considerada plenamente nos dias de hoje. Mesmo assim, vários experimentos realizados nesta área já são notáveis, constituindo-se em experiências válidas para lançar uma luz sobre o surgimento de determinados aspectos particulares na formação das manifestações patológicas. Revelam-se assim também as diferenças entre os gêneros, no que diz respeito aos quadros patológicos: nas mulheres, há uma maior incidência de manifestações insanas de cunho erótico e sexual e uma presença mais discreta dos delírios de grandeza, além da presença muito mais intensa de estados de excitação e de toda a espécie de alterações de humor. Esses fatos revelam a importância e o significado da vida sexual para a mulher, a situação limitada de seus anseios e de sua posição na sociedade, bem como de sua suscetibilidade emocional, muito maior e diferente da dos homens. Acrescente-se a isso a manifestação frequente de perturbações histéricas que, de um lado, mostram a vivacidade dos processos afetivos, mas, de outro, a falta de autocontrole e a presença do pulsional na descarga das tensões internas.

Muito mais variadas são as influências que a idade avançada exerce sobre as formas de manifestação da insanidade. A falta de colorido do quadro psíquico patológico do estupor juvenil [Paralyse] é conhecida. No entanto, é preciso mencionar também a frequente presença do reflexo de Babinski - ligado à primeira 
infância - e a manifestação não rara de inúmeros ataques epileptiformes, os quais podem ser relacionados ao fato de que, neste caso, é possível comprovar a existência de uma ligação com as enfermidades cerebrais decorrentes da sífilis. Também as manifestações clínicas da demência precoce (que se instalam na infância e que, efetivamente, constituem o início das "hebefrenias de enxerto" [Pfropfhebephrenien]) costumam ser muito pobres: idiotias simples, grotescas, às vezes acompanhadas de excitações de cunho pulsional - um sinal de que tanto aqui, como no estupor juvenil, os processos patológicos da vida psíquica na infância nem de longe encontram as possibilidades de expressão e de atuação da fase adulta. Não é preciso mencionar que, por um lado, as patologias destrutivas do cérebro juvenil parecem ser muito mais devastadoras, uma vez que exterminam células germinativas do desenvolvimento; por outro, no entanto, elas encontram formas de compensação mais favoráveis. Com muita frequência observamos nesta idade - e eventualmente até o final da segunda década de vida - a forte presença de determinadas moções pulsionais primitivas, as quais, em casos excepcionais, podem se manter por toda a vida. Enquadram-se aqui especialmente aquelas pulsões comparáveis ao ímpeto à liberdade presente nos animais - tais como o cabular aula, o perambular e o vadiar -, além da inclinação pela aventura que impele as crianças, armadas até os dentes, a fazer uma viagem a um país estrangeiro para dar um colorido às suas tendências a fantasiar e a se transportar para situações de vida fictícias. Também a pulsão tão comum nas crianças para comer fora de hora e para roubar deve ter suas raízes nas moções naturais de cobiça. Pode ser que muitas outras direções patológicas das pulsões permitam uma interpretação semelhante.

Já os anos de desenvolvimento, de uma maneira geral, imprimem a marca de excitações vivazes e de amuos aos quadros patológicos que surgem então - do mesmo modo como acompanham, por alusão, a manifestação das moções sexuais normais. A este fenômeno corresponde - no que diz respeito à criminalidade - 0 grande número de crimes bárbaros e de crimes passionais que ocorrem nessa fase de vida. Hecker afirma que também devemos enxergar na idiotia pueril um "colorir" da forma clínica, ocasionado pelo desequilíbrio característico da maturação sexual que se inicia - mas isso por ora ficará em suspenso. De qualquer modo, a frequência das perturbações histéricas sofre uma intensificação condicionada à força e à qualidade pulsional dos processos afetivos no domínio de uma vontade ainda pouco fortalecida. O colorido peculiar, ingênuo e arrepiante dos estados nebulosos histéricos lembra aquelas formas do drama cinematográfico tão ao gosto dessa faixa etária. A doença maníaco-depressiva, por sua vez, costuma assumir a forma de mania com relativa frequência. Na vida pulsional, os processos sexuais têm um papel dominante. A passagem do estado assexuado para a homossexuali- 
dade - ligada à recusa do sexo oposto e à bissexualidade, para, depois, chegar à direção pulsional normal - está atrelada ao perigo do deslocamento definitivo da meta sexual, que é ocasionado principalmente pela masturbação. Pode ocorrer então a fixação em algum dos degraus intermediários ou o resvalar para circunstâncias secundárias colaterais do fetichismo, ou, finalmente, para o sadismo e o masoquismo, como eventual consequência de moções pulsionais arcaicas, oriundas das lutas entre os gêneros.

As décadas que se seguem são marcadas principalmente pela frequência e pela riqueza dos quadros de insanidade, que se manifestam com mais frequência de forma interiormente trabalhada, subjugando a vida mental - ao passo que, se ocorrem mais cedo, costumam ser mais superficiais e mais incoerentes. Encontramos este processamento mental vivaz das relações da existência nas mais diversas formas de doença na idade madura, nos estados maníaco-depressivos e no estupor, bem como na demência precoce e, sobretudo, na paranoia - característica justamente dessa fase de vida. É provável que reencontremos aí a tendência da fase mais madura de posicionarmo-nos diante do mundo que nos cerca, de criar uma concepção de mundo e de vida. A maior independência e a maior responsabilidade na condução individual da luta pela vida automaticamente forçam o indivíduo a avaliar as influências do meio em seu significado para o seu próprio bem. Esta direção do pensamento também deveria saltar aos olhos nas manifestações de insanidade, no falseamento das memórias e nas alucinações dos sentidos, pois os desejos, os medos e os anseios adquirem uma forma concreta. Diante disso, os transtornos da vontade característicos da demência precoce tornam-se menos presentes, talvez porque os traços básicos da vontade já há muito se encontrem firmados e cristalizados. Nas diversas formas da insanidade maníaco--depressiva, os estados melancólicos conseguem lentamente ganhar em importância, na mesma proporção do lento desaparecer da alegria esperançosa da juventude e do ímpeto à luta, da visão mais séria e mais pessimista da vida e do aumento geral no número de suicídios na idade mais avançada.

Essa mudança no estado de espírito se fortalece de maneira significativa especialmente nos anos em que os indivíduos sofrem perdas - e particularmente na mulher, com a interrupção abrupta da vida sexual. As manifestações de insanidade nas mais diversas formas patológicas, que também são frequentes nesta fase, revelam um conteúdo predominantemente depressivo. No sexo feminino, não raro o colorido erótico ou sexual lembra o recrudescimento das moções sexuais das mulheres que envelhecem. Aos poucos, parecem tornar-se mais e mais presentes as sensações de fracasso, o sentimento de desamparo e a insuficiência corporal nas sendas do pensamento doentio, no delírio do empobrecimento e nas fantasias nihilistas e hipocondríacas - que, nos jovens, estão muito distantes. Nem é preciso 
comentar aqui que os quadros patológicos são dominados, paralelamente e cada vez em mais larga medida, pelos efeitos secundários de processos destrutivos.

Por outro lado, até hoje ainda permanecem praticamente inexploradas as correlações entre o senso comum e as formas de insanidade, embora estas representem riquíssimas fontes de conhecimento. Já se apontou muitas vezes, por exemplo, para o fato de que os quadros patológicos surgidos entre os judeus - especialmente entre aqueles vindos da Europa oriental - não raro apresentam traços desviantes, "degenerativos" e histéricos - mas uma descrição mais exata destas particularidades ainda não foi possível. Ademais, parece que determinadas diferenças podem ser observadas no comportamento dos doentes mentais de países e de culturas diversas - mas também faltam pesquisas mais aprofundadas para comprová-lo; e estas, por sua vez, também oferecem muitas dificuldades em virtude da heterogeneidade da população nas instituições. Alguma coisa, porém, sabemos a respeito das formas de manifestação das doenças observadas aqui e ali - e que certamente pertencem, em boa parte dos casos, à categoria dos transtornos histéricos. Nada sabemos, entretanto, das relações existentes entre estas manifestações e as características emocionais dos respectivos povos. Minhas observações em Java mostraram-me que a psiquiatria comparada pode levar a importantes descobertas. Pareceu-me bastante extraordinário o fato de que entre os nativos doentes de Java parecem inexistir completamente as melancolias - enquanto pude diagnosticar estados maníacos em grande número. Acrescente-se a isso também o fato de que, entre aqueles pacientes, o suicídio é praticamente desconhecido. Evidentemente também não existe a paranoia de cunho religioso, que tem sua origem nas representações religiosas; de modo geral, não encontrei nenhuma espécie de moção que pudesse corresponder aos nossos fortes sentimentos de culpa ou responsabilidade. A demência precoce, que constitui a maioria predominante das formas de doença, pareceu-me ser decorrente de confusos estados de êxtase, ao passo que o estupor negativista, tão frequente entre nós, praticamente inexiste. Alucinações auditivas quase que inexistem, talvez pelo papel pouco importante que a língua desempenha no pensamento dos doentes daquela cultura. Também as alucinações, de modo geral, pareceram-me ser muito mais raras e insignificantes do que o são em nosso meio, talvez porque a necessidade de elaborar as vivências intelectualmente e de forma mais ampla é menor entre eles.

As formas de manifestação da insanidade - pelo menos entre nós - seriam de longe mais influenciadas pelas idiossincrasias dos pacientes. A infinita diversidade na constituição e nos destinos da vida imprime em cada indivíduo uma marca psíquica específica, que só a ele pertence e que, por natureza, também se faz presente nas manifestações patológicas. De uma maneira bastante genérica, isto já fica visível no fato de que cada conteúdo insano se origina a partir do universo de repre- 
sentações do paciente; contudo, a própria forma das emoções e das manifestações da vontade, que se radicam na personalidade existente previamente à doença, também pode trazer consigo as mais fortes destruições, deslocamentos e reviravoltas.

Fica claro, portanto, que a compreensão das manifestações patológicas deverá passar primordialmente pela pesquisa das disposições herdadas. A coincidência muitas vezes surpreendente nos quadros patológicos de parentes próximos tais como irmãos, pais e filhos - fala a favor disto. No entanto, se quisermos obter uma compreensão mais profunda destas ligações, será preciso, evidentemente, pesquisar as disposições inatas muito mais para trás do que normalmente se consegue ir ou do que é possível ir. Não podemos esperar que aquelas influências constituintes de uma determinada personalidade possam ser encontradas justamente nos últimos poucos membros de uma numerosa família, pois encontramos em nossa constituição corporal e emocional inegáveis traços de patamares de desenvolvimento muito longínquos. Parece correto supor que um considerável número de quadros patológicos pouco nítidos e ambíguos poderia encontrar uma explicação na mescla de traços herdados, que trazem consigo características bastante peculiares. Dessa forma - e de acordo com a suposição de Rüdin - a multiplicidade dos quadros de estupor teria sua explicação no fato de que em determinado caso o processo destrutivo se desenrola sobre uma base maníaco-depressiva herdada de qualquer das partes e, em outro caso, sobre uma base influenciada pela catatonia. Da mesma forma o tão frequente colorido esquizofrênico presente nas patologias maníaco-depressivas, a manifestação de quadros maníacos nos epiléticos e muitas outras experiências clínicas que chamam nossa atenção - e que são difíceis de explicar - poderiam eventualmente surgir por esse mesmo caminho. De qualquer maneira, temos diante de nós uma questão importante, que nos oferece estímulos e perspectivas para chegarmos a novas descobertas.

É óbvio que, além das disposições inatas, uma série de outras influências pode atuar sobre a formação da personalidade psíquica, começando pelos danos embrionários e as doenças dos primeiros anos de vida, até chegar às mudanças que são provocadas pela educação e pela aquisição de conhecimentos, pelo entorno e pelo destino. Todas essas influências podem se mostrar presentes quando da descrição clínica dos quadros patológicos, nessa ou naquela direção, mesmo que, em detalhe, ainda saibamos muito pouco sobre isso. Um exemplo claro são as aberrações sexuais, mais especificamente o fetichismo, no qual muitas vezes podemos constatar um desenvolvimento extravagante das tendências sexuais depois de determinadas vivências impressionantes - quando do despertar da pulsão sexual. Outros quadros patológicos que obtiveram sua forma peculiar a partir de determinadas circunstâncias de vida são as psicoses decorrentes de aprisionamento e privação de liberdade e o delírio queixoso. As manifestações de recalcamento nos 
indivíduos com prisão preventiva decretada apoiam-se no desejo natural de todos os acusados de, na medida do possível, esquivar-se do torturante inquérito e provar sua inocência. $\mathrm{O}$ aspecto semelhante da psicose de aprisionamento - decorrente de processos patológicos totalmente diversos - já foi bastante destacado; ela surge pela violenta pressão, comum a todos, causada pela perda da liberdade e pela submissão impotente à violência do Estado. Algo parecido ocorre com o delírio de inocência e de perdão em prisioneiros idosos, nos quais se manifesta a expressão do desejo de fugir da condição de vida insuportável. Vemos surgir o delírio queixoso de forma absolutamente idêntica nos merceeiros de processo [Prozesskrämern], nos prisioneiros e nos caçadores de pensões [Rentenjägern] como uma consequência do ardoroso desejo de, por todos os meios, conseguir fazer valer supostos direitos legais.

Esta rápida visão geral sobre as condições de surgimento das manifestações da insanidade nos ensina que em todas as situações - conforme Birnbaum já descreveu em profundidade - precisamos contar com "formas de manifestação" junto dos "transtornos de base" resultantes da verdadeira causa da doença, nos quais as particularidades inatas bem como as características adquiridas da personalidade adoecida conseguem se manifestar.

Grosso modo, talvez seja possível fazer uma distinção entre estes dois aspectos integrantes dos quadros clínicos: de um lado, considerando aqueles transtornos - que sem exceção sempre voltam a ocorrer no mesmo processo patológico - como efeito direto dos problemas que estão na sua base; e, de outro lado, considerando aquelas manifestações mutáveis - que ora estão presentes sob esta ou aquela forma, e ora estão ausentes - como resultantes das idiossincrasias do próprio doente. Da mesma maneira, o significado de inúmeros sinais corporais que saltam à vista também poderia ser útil para o reconhecimento de determinados processos patológicos, uma vez que estes sinais estão em uma relação muito mais estreita com as influências causais do que os transtornos emocionais.

No entanto, o ponto de vista por ora mais evidente que aqui desenvolvemos necessita de importantes restrições. De um lado fica evidente que os transtornos de base provocados diretamente pela causa da patologia - dependendo da intensidade, do tempo de duração e da disseminação das influências patogênicas - também devem estar sujeitos a consideráveis gradações e oscilações. Contudo, muito mais significativo é o fato de que, por outro lado, inúmeras formas de manifestação da insanidade são definidas de uma vez por todas por meio de dispositivos-modelo do organismo humano, que se comportam da mesma maneira em todos os lugares em que as pré-condições para tal estão presentes. Pois ao lado das idiossincrasias puramente pessoais, as qualidades humanas típicas dos doentes assumem um caráter preponderante. Podemos então contar com o fato de que uma parte sig- 
nificativa das formas de manifestação sempre volta a ocorrer nos processos patológicos - pela simples razão de que elas representam a resposta natural da máquina humana àquela incursão que faz com que ela adoeça.

Além do mais, a origem deste tipo de manifestações patológicas a partir de dispositivos-modelo reiteradamente se revelará pela circunstância de que elas não se limitam a um processo patológico determinado, mas podem ser provocadas da mesma forma por influências patogênicas de inúmeras espécies. Aqui deveria residir a mais importante fonte das infinitas dificuldades, quase intransponíveis, contra as quais o reconhecimento dos processos patológicos a partir de sintomas clínicos precisou lutar - desde os primórdios, até a atualidade. Se estivéssemos lidando apenas com os transtornos de base de causa conhecida, mesmo que eles variassem em intensidade, em alcance e em formas de desenvolvimento, nossa tarefa seria relativamente fácil de resolver. Mesmo as contribuições estritamente pessoais aos quadros patológicos não nos criariam dificuldades em função de sua inconstância, de sua falta de padronização e de sua multiplicidade nos modos de apresentar-se. Em contrapartida, a valoração das manifestações patológicas para o reconhecimento dos processos que estão em sua base deve tornar-se quase impossível, se conseguirmos discernir nas mesmas apenas as tonalidades genéricas próprias com as quais o indivíduo responde aos transtornos das mais variadas espécies. Nestas circunstâncias, somos forçados a restringir ao máximo o pressuposto de que este ou aquele transtorno é característico de um determinado processo patológico. Contudo, as manifestações patológicas guardarão para nós um determinado valor esclarecedor. Mesmo que suas idiossincrasias não sejam determinadas de forma decisiva pelas causas nosológicas, mas, em essência, pelas disposições de nosso organismo, suas diferenças devem de alguma forma estar em uma relação de dependência com as modalidades de agressão e disseminação dos processos patológicos. Cada doença, neste sentido, deve ter suas próprias particularidades. Portanto, devemos supor, sim, que a um determinado sofrimento correspondam determinadas formas de manifestação - não porque os processos patológicos os provoquem diretamente, mas porque, segundo a experiência, eles criam condições que são muito propícias ao surgimento dessas manifestações. Além disso, sempre ainda encontraremos casos nos quais - por um deslocamento dessas condições outras formas de manifestação se mesclarão ou passarão a ser preponderantes.

Dessas explanações depreendemos que é necessário tentar obter uma visão mais aprofundada daquelas formas de manifestação de insanidade que com razão atribuímos ao jogo das disposições inatas de nosso organismo - e que destarte se repetem em diversas doenças de maneira semelhante -, embora com frequência e expressão bastante variáveis. É óbvio que se trata aqui de uma tarefa dificílima para cuja solução temos à disposição apenas alguns meios auxiliares ridículos. 
Algum suporte nos é dado pela comparação das manifestações patológicas com as experiências que fazemos com crianças, com raças humanas subdesenvolvidas e também com animais; aí fica claro que se manifestam em nossos pacientes transtornos encontráveis em formas semelhantes em patamares mais baixos de desenvolvimento psíquico que revelam relações com idiossincrasias de caráter genérico em nossos mecanismos internos. Se nos guiarmos pela Teoria da Evolução, principalmente da maneira como nos é demonstrada pela história do surgimento da vida psíquica individual, somos forçados a pressupor que as ferramentas psíquicas colocadas à disposição do adulto representam a manifestação de inúmeros degraus de aperfeiçoamento progressivo. Além disso, inúmeros resquícios desse desenvolvimento sem dúvida permaneceram e podem ser reestimulados por meio de excitações doentias, para realizações há muito recalcadas. Por outro lado, pela destruição e paralisação de dispositivos superiores, ferramentas muito antigas - que nos indivíduos sadios eram dominadas e utilizadas - podem conquistar uma autonomia indesejada e influenciar significativamente o quadro patológico. Em ambos os casos poderá haver uma aproximação camuflada - e, aliás, bastante desgastada por fusões de ordem estranha - das formas de expressão patológicas nas manifestações da vida psíquica não desenvolvida.

Por menos que atualmente não estejamos em posição de prosseguir na busca de respostas a esta questão - dado à falta de uma psiquiatria comparada -, queremos fazer uma tentativa de analisar rapidamente algumas das formas de manifestação da insanidade mais frequentes, a fim de oferecermos uma explicação dos pontos de vista aqui desenvolvidos, com a finalidade de estimular novas pesquisas a respeito.

Em primeira linha, queremos lembrar do caso detalhadamente descrito por Bonhoeffer, no qual uma série de danos provindos do exterior, tais como envenenamentos e infecções, penetrou no córtex cerebral produzindo quadros patológicos que mostram diversos traços em comum. Peço permissão para falar aqui em uma forma delirante de manifestação de insanidade. As manifestações são basicamente aquelas de uma turvação mais ou menos forte da consciência, com dificuldades de compreensão, falta de clareza, perturbações sensoriais principalmente no rosto, mas também da audição, vivências semelhantes às que ocorrem no sonho, confusão de pensamento, humor variável, com presença de medo, mas também eufórico ou irritadiço e, finalmente, com presença de estados de excitação ou renúncia à manifestação da vontade. Certamente a descrição destes quadros patológicos encontra-se em estreita dependência dos transtornos causais que, assim como nos delírios alcoólicos, reconhecemos a partir de determinados traços individuais. Ainda assim, parece-me inegável que as manifestações patológicas se deem em formas cujos pressupostos se encontram nas características gerais da vida psíqui- 
ca. Para fortalecer esta ideia, chamo especialmente a atenção para as vivências dos sonhos, cuja ampla concordância com os delírios é bastante evidente. Podemos afirmar que nosso cérebro responde simetricamente a uma série de diferentes danos, principalmente exteriores, na forma típica dos estados oníricos e com modificações ocasionadas pela falta do sono que habitualmente acompanha o sonho, bem como por determinadas particularidades das influências causais.

Com certeza poderíamos levantar a objeção de que a concordância mencionada não é ocasionada pela origem em comum - a partir dos pressupostos psíquicos existentes - mas pela semelhança entre as causas que concorrem para a produção de sonhos e delírios. Uma vez que no surgimento dos delírios as substâncias tóxicas - mesmo aquelas resultantes das trocas metabólicas - desempenham um importante papel, poderíamos chamar a atenção para o fato de que tanto o sono, como o sonho, é suscitado por produtos semelhantes resultantes das trocas metabólicas, mesmo sendo eles de ação muito mais fraca. A isto podemos objetar que, para que surja o sono de um lado e, de outro, a turvação da consciência, um raciocínio semelhante talvez pudesse ser permitido; mas, que o sonho represente apenas a continuidade da vida psíquica sob condições especiais inerentes ao sono, deve ser encarado como um produto difícil, porém imediato, das influências que nos fazem dormir; pois nossos sonhos mais vivazes ocorrem quando o sono é ainda, ou novamente, leve. Mas devemos chamar a atenção especialmente para o fato de que estados delirantes bastante semelhantes podem ocorrer sob condições totalmente diversas, não só em decorrência de substâncias tóxicas, nas infecções, na febre, nos acidentes cerebrais, mas também em epiléticos, em paralíticos, em maníaco-depressivos, na demência precoce, na senilidade, bem como na histeria e na hipnose. Essas experiências nos mostram claramente que os delírios pertencem às formas de manifestação de insanidade cujas bases se encontram nas idiossincrasias da vida psíquica original. Eles surgem em lugar do pensamento claro e consciente, assim que a consciência é turvada sob a influência de quaisquer processos patológicos. Não é de estranhar o fato de que aí a configuração especial do delírio seja influenciada não só pela história pregressa do paciente, mas também pelas peculiaridades dos processos patológicos causais.

Um segundo grupo de formas clínicas de manifestação caracteriza-se pela elaboração paranoica das experiências de vida. Deparamo-nos com ela principalmente na paranoia, mas também nos diversos tipos de queixosos, nas psicoses de prisão, nas perturbações mentais delirantes por abuso de álcool e de cocaína, bem como na demência precoce e nas parafrenias, e, além disso, com frequência nas insanidades maníaco-depressivas e na idade senil. A base genérica do pensamento paranoide aparentemente deve ser buscada na forte influência da sequência de ideias por carências emocionais e, portanto, no colorido pessoal das 
visões de mundo. Todo indivíduo, para se afirmar em sua luta existencial, necessita de confiança em si mesmo e de desconfiança em relação ao ambiente potencialmente inamistoso. Daí resulta a tendência natural de supervalorizar a própria pessoa e de se comportar de maneira relutante ou, mesmo, inamistosa diante do estranho e, além disso, de se colocar diante de todos os eventos externos de modo que revertam em benefício próprio. Acrescente-se ainda, para terminar, a certeza ingênua do pensamento não desenvolvido que não conhece a dúvida, mas que, sem mais, aceita toda suposição que surge como sendo a expressão da verdade. Só a experiência mais amadurecida fornece, aos poucos, os parâmetros corretos para a avaliação da relação entre a própria pessoa e o ambiente. A importância da pessoa encolhe na mesma proporção em que aumenta o seu horizonte - e os acontecimentos externos perdem sua íntima conexão com ela. No lugar da compreensão puramente pessoal entra o julgamento isento que procura livrar-se mais e mais da influência das carências emocionais. Finalmente, a partir da revelação dos enganos assim obtida, desenvolve-se a mola-mestra de todo reconhecimento progressivo, que aceita a dúvida e que não admite certezas sem uma incansável comprovação, utilizando-se de meios auxiliares de investigação cada vez mais refinados.

A coincidência nas formas delirantes de manifestação de insanidade dos pacientes por nós observados, com a presença de demônios e pensamentos mágicos característicos dos povos subdesenvolvidos, é marcante. Outras lembram mais os imponentes castelos no ar e as grandiosas realizações, características da fase da juventude; outras, ainda, a desconfiança pouco amistosa contra estranhos, como aquela demonstrada por povos selvagens e por crianças pequenas. A isso se acrescenta muitas vezes ainda a influência da compreensão e do processamento psíquico através do estado de humor, a interpretação das vivências no sentido das esperanças e dos medos reinantes. Nessas circunstâncias, poderia chamar a nossa atenção o fato de não encontrarmos com frequência formas mais elaboradas de manifestações paranoicas em crianças e aparentemente também nos povos menos desenvolvidos mentalmente. A razão disso pode estar no fato de que o trabalhar mais superficial e mais emocional das vivências é menos propício ao processamento paranoico; antes, este último parece pressupor a formação de uma visão de mundo mais abrangente e de certa forma mais concatenada, da qual são retirados os parâmetros e estímulos para o julgamento paranoico.

É certo que as formas mais frequentes de manifestação da insanidade moldem as expressões de sentimentos doentias. Elas predominam no quadro no distúrbio maníaco-depressivo e na histeria, mas têm também um importante papel no estupor e na demência precoce e podem eventualmente dominar a cena em praticamente todos os demais transtornos mentais. É preciso admitir que estados de humor 
doentios, conforme já mencionamos, podem ser originados diretamente por determinadas causas, especialmente por substâncias tóxicas. Contudo, suas emanações psíquicas e suas descargas movimentam-se em trilhos pré-formados e, por essa razão, ressurgem em todos os lugares da mesma forma, totalmente independentes da causa a partir da qual a moção emocional se formou. É assim que ocorrem os movimentos expressivos na postura, nos traços fisionômicos e nas mímicas, que trazem consigo dor e preocupação, medo, raiva, alegria e euforia. A eles acrescentem-se as atitudes determinadas por moções emocionais, tais como discursos e textos escritos, bem como as ações de desprezo, as tentativas de aproximação e rejeição, os atos violentos, o suicídio e as ações de proteção ligadas à religião. Junte-se, ainda, a influência da compreensão da consciência correspondente, dos caminhos de pensamento e do conteúdo das representações, a falta de compreensão e de clareza, a captura isolada ou o acúmulo de inúmeras representações, o julgamento mais cor-de-rosa ou mais cinzento do passado, do presente e do futuro. Uma parte significativa das formações paranoicas por nós observadas certamente se origina das influências emocionais; possivelmente, no sentido mais amplo, isto valha para todas. Talvez possamos separar - como era o caso antigamente - as alucinações decorrentes de alterações de humor mais passageiras, "catatímicas" daquelas alucinações paranoicas que têm suas raízes em carências emocionais mais duradouras. Aqui existem pontos de contato entre as formas de manifestação de insanidade paranoicas e "emocionais".

O conteúdo das representações recebe uma influência curiosa dos medos que se originam a partir das ameaças gerais à vida e à saúde, das relações recíprocas entre as pessoas e do enorme senso de responsabilidade decorrente da educação religiosa, dos costumes e da lei. Eles sabidamente podem tornar-se uma pressão insuportável, que influencia amplamente a ação. Aparentemente, todos estes medos compulsivos se originam de fontes que já se encontravam disponíveis e que agora inundam a vida psíquica em uma medida não desejada.

As formas emocionais de expressão estão em uma relação de parentesco bastante próxima das manifestações patológicas histéricas. Os afetos se descarregam não só nas manifestações da vontade, mas também naqueles processos que habitualmente - ou mesmo permanentemente - fogem à influência direta da vontade. A musculatura da pupila, do estômago e do intestino, dos cabelos, dos vasos sanguíneos; o batimento cardíaco, a respiração, a atividade das glândulas lacrimais e sudoríparas, as glândulas do estômago e do intestino, talvez também do fígado e dos rins, podem ser abalados por tensões e comoções emocionais. Acrescentem-se aí ainda as limitações nos movimentos arbitrários, tremedeira, fraqueza, insegurança, catatonias, espasmos e, finalmente, colapso dos sentidos e turvação da consciência com confusão delirante. Todas essas formas de 
descarga que, nas pessoas saudáveis, aparecem apenas em forma de alusão e podem ser facilmente controladas, na histeria alcançam sua mais pronunciada manifestação. Conforme já mencionado em outra parte, elas possivelmente devam ser encaradas como remanescentes de dispositivos arcaicos de proteção e de defesa, pertencentes a um degrau de evolução já ultrapassado. Assim, de certa forma elas constituem um ramo das formas emocionais da manifestação de insanidade, que entra em funcionamento quando as comoções emocionais são muito fortes e, portanto, praticamente não conseguem irradiar por outros canais, ou quando o controle dos afetos por meio da vontade é insuficiente como, por exemplo, nas crianças, nas mulheres, nos degenerados, nos alcoólatras.

O grupo das formas pulsionais de manifestação de insanidade também nos conduz a uma camada mais profunda do desenvolvimento da vontade. Entendemos por formas pulsionais de manifestação de insanidade aquelas moções da vontade com uma forte conotação afetiva, que impulsionam o indivíduo para a execução de determinadas ações, sem que uma motivação tenha passado pela razão. Nas pulsões temos diante de nós formas arcaicas do querer, nas quais o objetivo não é estipulado pela ponderação, mas por necessidades que se fazem presentes com um enorme poder. Inúmeras pulsões devem ter surgido e desaparecido ao longo do desenvolvimento da raça humana. Entre nós, a vida pulsional se limita quase que exclusivamente ao instinto de conservação da espécie e aos diversos instintos de conservação do indivíduo. Em todos os outros aspectos, as moções pulsionais foram empurradas para os bastidores por enérgicos atos de vontade. Mas em solo doentio, as pulsões sufocadas podem adquirir novas forças. Tomemos como exemplo a pulsão sexual, que costuma ficar adormecida até a entrada na puberdade; nos oligofrênicos e psicopatas, conforme as circunstâncias, ela pode se manifestar muito precocemente - e a isto se atrela, então, o perigo dos descarrilamentos. Já os desvios sádicos e masoquistas, conforme sugerimos, provavelmente estão relacionados a moções pulsionais há muito superadas. Também já mencionamos que o instinto de liberdade - fortemente presente nos animais - continua a existir no gazetear típico das crianças e em determinadas formas de deambulação nos adultos, mais ou menos subjugados pela educação ao senso de responsabilidade. A inclinação natural e de caráter pulsional da criança de se apoderar daquilo que lhe agrada, vemos transformar-se em delitos contra a propriedade com fortes chances de recidiva quando o desenvolvimento da vontade é fraco. Algo semelhante ocorre na tendência infantil de inventar e de disfarçar e evidentemente nas formas mais desenvolvidas e preocupantes no restante do amadurecimento da personalidade dos mentirosos e trapaceiros natos. Faltaria esclarecer se a pulsão por provocar incêndios, que de vez em quando observamos, também possui raízes históricas semelhantes; as conexões com a "saudade de casa" 
poderiam servir de prova. De qualquer maneira eu suponho que, assim como na saudade, os "amuos" tão frequentes nos psicopatas e nos epiléticos na realidade deveriam ser considerados como moções pulsionais sombrias. Elas muitas vezes conduzem a atitudes compulsivas, como, por exemplo, ao viajar sem sentido e ao ato de beber.

Se nas formas de manifestação de insanidade até agora discutidas tratou-se principalmente de vestígios de patamares de desenvolvimento mais precoces - que se destacaram por terem sido dominados de maneira insuficiente por mecanismos mais perfeitos -, então as ferramentas inferiores da vida psíquica também podem conseguir uma autonomia defeituosa pela destruição de êxitos mais elevados. Este ponto de vista talvez seja apropriado para nos revelar inicialmente uma compreensão para aqueles transtornos que chamamos de esquizofrênicos, porque na demência precoce costumam ser desenvolvidos ao máximo. Trata-se aqui principalmente da destruição da vontade enérgica, do mesmo modo como fica nítida na extinção da atividade, das ambições e na perda da coerência interna das manifestações da vontade. Essa falta de direção conduz em primeiro lugar a uma atividade movida pelo pulsional: as manifestações de vontade que surgem não são reprimidas em função de um pensamento organizado, nem conduzidas para as vias corretas, mas se impõem sem nenhuma consideração, da mesma maneira como surgiram; mas elas também atravessam o desenvolvimento da ação de muitas formas, de modo que surgem todas aquelas extravagâncias que chamamos de "maneiras". Mas, além disso, algumas direções originais da vontade recebem uma influência decisiva, que normalmente é dominada por toda a personalidade e usada a seu favor. Na estereotipia isso fica muito evidente. A tendência à repetição uniforme da mesma ação é uma particularidade genérica das ferramentas da vontade que costuma ser bastante visível em crianças, mas que, além disso, se revela especialmente no significado fundamental do ritmo para todas as atividades humanas. Também a automação dos comandos e o negativismo podem ser explicados de maneira semelhante. É lícito supor que, no desenvolvimento da vontade, inicialmente se constituirão duas tendências básicas opostas entre si: a exposição a influências externas e o rechaço das mesmas. Inicialmente pensaremos que a escolha entre essas duas possibilidades seria de ordem pulsional, até que uma experiência mais amadurecida e a vontade enérgica por ela regida aprendam a distinguir as influências fomentadoras das influências adversas. Assim que essas últimas são desligadas, como é o caso na hipnose, podemos ver surgir facilmente a oposição entre a resistência ferrenha e a submissão abúlica.

Os movimentos expressivos dos doentes, suas palavras, gestos, escritos, desenhos e mímica costumam oferecer estereotipia e maneirismo nas mais diversas formas. Além disso, somos frequentemente confrontados com desenfreados neo- 
logismos, que se libertaram totalmente da influência reguladora das imagens habituais. Talvez possamos pensar que neologismos lúdicos dessa espécie devem ter formado o pressuposto para o surgimento dos meios de entendimento em geral. Eles forneciam - tal como podemos observar em nossas crianças - a matéria-prima a partir da qual lentamente se formaram conexões mais sólidas entre determinados processos psíquicos, de modo que uma transmissão se tornou possível.

As formas de manifestação da esquizofrenia não se limitam apenas à demência precoce. Nós as reencontramos - mais ou menos pronunciadas - principalmente em alguns processos patológicos com vastas destruições do tecido nervoso, como, por exemplo, no estupor, ou na idiotia senil, eventualmente também em patologias cerebrais traumáticas circunscritas. Sem dúvida podem surgir também manifestações esquizofrênicas sem que ocorra a destruição de tecido cerebral. Se quisermos deixar de lado as experiências da hipnose, existe ainda outro fato que o comprova: o de que reencontramos todas essas formas de manifestação na criança, tais como a recusa de caráter pulsional, a submissão abúlica, as manifestações de vontade de caráter também pulsional, a tendência à repetição uniforme, à variação lúdica dos movimentos e, em especial, à criação de neologismos - assim como costuma acontecer na iniciação à linguagem. Mais um indício nos é fornecido pelo fato de que a linguagem dos sonhos, com os seus neologismos, trocadilhos e disparates no plano da fala e do pensamento, corresponde em todos os detalhes à confusão de linguagem esquizofrênica. O simples desligamento de tarefas mentais mais elevadas conduz, nesse campo parcial, aos mesmos resultados que no processo de destruição da demência precoce. Essa constatação tem grande importância porque aponta para a possibilidade de que, em determinadas circunstâncias, outras patologias podem assumir formas de manifestação esquizofrênicas.

A fala alucinatória como forma de manifestação de insanidade parece estar ligada à fala esquizofrênica - de um modo que até hoje não sabemos explicar melhor - no que tange ao aparecimento de ilusões auditivas, em formato de argumentos e contra-argumentos. Este sintoma é sabidamente o mais frequente nas patologias esquizofrênicas, bem como nas parafrenias, suas parentas próximas; contudo, deparamo-nos com uma forma bastante semelhante no delírio alcoólico, na demência causada pela cocaína e em algumas patologias cerebrais decorrentes da sífilis; às vezes também no estupor e também na paranoia dos deficientes auditivos e dos prisioneiros. Eu deixaria em suspenso, por enquanto, a questão se as ilusões auditivas observadas até agora na insanidade maníaco-depressiva se assemelham, em essência, aos fenômenos acima descritos. Pode-se inferir, naturalmente, que nas doenças mencionadas os sintomas de irritação são deflagrados nas áreas cerebrais responsáveis pela fala, mas é certo que esta forma especial, bem como o conteúdo das ilusões, tem origem nas condições psíquicas preexistentes. A uni- 
formidade das ilusões auditivas em patologias totalmente diferentes fala a favor de uma influenciação por medos e desejos humanos bastante genéricos. Seu conteúdo é por um lado ofensivo, irritante, ameaçador e, por outro, consolador, encorajador, congratulante e, muito raramente, indiferente ou sem sentido: perseguidores invisíveis, demônios ou poderes celestiais, anjos da guarda, amantes secretos, grandes protetores etc. Geralmente estão presentes estreitas relações com as cadeias de pensamento paranoicas.

Naturalmente os processos patológicos mais destrutivos - tais como a arteriosclerose, a sífilis cerebral e o estupor - produzem principalmente déficits de ordem psíquica, mesmo que muitas vezes também estejam presentes manifestações de irritação, estados de exaltação e espasmos; além disso, o fato de que frequentemente observemos quadros sintomáticos que se assemelham aos quadros maníaco-depressivos ou catatônicos poderia estar ligado à propagação de modificações patológicas de diferentes ordens, as quais - dependendo do caso - também concorrem para a deflagração de formas de manifestação emocionais ou esquizofrênicas. E uma elevada suscetibilidade, em função de uma predisposição pessoal, para esta ou aquela direção também poderia ter um papel decisivo. Finalmente, existe ainda um determinado número de transtornos nesses processos de demência que frequentemente são recorrentes e nos quais se manifestam realizações autônomas de ferramentas psíquicas subjugadas, destituídas de seu controle; podemos resumi-las como formas encefalopáticas de manifestação de insanidade. Encaixamse aí o preenchimento de lacunas de memória com invenções tiradas dos hábitos do cotidiano exatamente como as encontramos em crianças, o prender-se a pensamentos, palavras e ações, à logoclonia [Logoklonie], o cumprimento por meio de um sacudir rítmico das mãos, o choro e o riso compulsivos e rítmicos, provenientes do reflexo de sucção da primeira infância e talvez também a atetose [Athetose], que nos lembra dos movimentos lúdicos dos dedos em crianças pequenas. Os disparates das parapraxias e das parafrasias podem ser compreendidos sob o mesmo ponto de vista. Em muitos aspectos, eles correspondem às primeiras tentativas de agir e de falar da criança, à qual ainda falta o comando por meio de fórmulas preparatórias na ação e na fala; são as manifestações desordenadas das ferramentas da vontade, que mais tarde - e aos poucos - se disciplinam sob o domínio da personalidade assertiva. Elas formariam uma contrapartida a algumas manifestações neurológicas patológicas que costumamos atribuir à supressão da influência do córtex cerebral, ao aumento dos reflexos nervosos, ao surgimento do reflexo de Babinski, à formação de contrações espásticas, ao esvaziamento involuntário da bexiga e do intestino. Concordemos em detalhe - ou não - com todas estas tentativas de interpretação, parece-me que seja certo que uma parte dos sintomas nas destruições mais extensas do córtex cerebral não é provocada diretamente por es- 
tas, mas deve o seu surgimento ao mecanismo das ferramentas psíquicas, que se tornou sem direção. Essas manifestações frequentemente apontam para um patamar de desenvolvimento mais arcaico que as esquizofrênicas. Dessa forma, os processos patológicos aqui considerados parecem alcançar - ainda mais fundo que os outros - a construção em camadas das bases psíquicas; e não raro eles acabam por destruir as possibilidades de expressão mais arcaicas.

Há um outro grupo diretamente aparentado com essas manifestações colaterais de processos destrutivos, que se junta a esses bloqueios de desenvolvimento psíquicos e que, por isso, podemos chamar de formas de expressão oligofrênicas. Aqui também estamos lidando com efeitos destrutivos, mas eles acometem o cérebro ainda não formado e, assim, deterioram suas estruturas em maior ou menor extensão. Portanto, de maneira ainda mais chamativa que na forma anterior, o jogo das disposições subalternas tem a possibilidade de participar por conta própria, a fim de imprimir ao quadro patológico a sua marca. São principalmente as características infantis que se mantêm, aquelas que normalmente são superadas pela intervenção da personalidade desenvolvida. Como exemplo, poderíamos mencionar o controle insuficiente do intestino reto e o da bexiga, os movimentos desajeitados e ainda o balbucio, a gagueira e o desenvolvimento deficitário da fala. Apenas por meio do trabalhar direcionado da vontade é que estas capacidades lentamente se ajustam às necessidades crescentes e se refinam. Onde este trabalho não existe, as formas de manifestação se mantêm em um patamar mais baixo. Entre elas, inclui-se um grande número de moções pulsionais que relembram costumes arcaicos, animalescos que, entretanto, especialmente pelo seu desenrolar rítmico, apontam para o modo de ação autônomo de ferramentas pré-formadas. Aí se enquadram o roer unhas, o puxar, o rasgar - mas também o saltar, o pular, o ninar, o abanar, o estalar da língua, o bater palmas, o menear da cabeça, o bater, o limpar uma superfície, o ranger os dentes. É digno de nota quantas vezes reencontramos essas manifestações patológicas também nas outras formas pesadas de demência, como, por exemplo, o ranger dos dentes presente nas últimas fases do estupor, o puxar, o roer e o rasgar da esquizofrenia. Também por isso fica evidente que não estamos aqui lidando diretamente com manifestações patológicas, mas com a liberação de moções arcaicas pela destruição das influências superiores da vontade. Além disso, existe a suspeita de que os assim chamados movimentos dementes dos oligofrênicos frequentemente podem ser tomados como expressão da manifestação prematura de demência precoce.

Finalizando, temos ainda que examinar sinteticamente um grupo de manifestações patológicas circunscritas, nas quais também nos deparamos com a evolução de um tipo de movimento que se instala de determinada maneira, desencadeado por influências de ordem totalmente diferente: refiro-me aos espasmos epileptoides. 
Justamente nessa forma de manifestação "espasmódica" fica bem claro que a manifestação clínica é - em alto grau - independente da essência do processo patológico. $\mathrm{O}$ ataque com contrações pode se desenrolar de maneira exatamente idêntica, quer estejamos buscando sua causa em uma infecção, uma intoxicação ou uma doença cerebral disseminada - ou quer estejamos lidando com uma sífilis cerebral, uma uremia, um alcoolismo severo, uma esclerose tuberosa ou uma epilepsia genuína. Tampouco podemos esquecer que as emoções e a simulação consciente também apresentam o mesmo quadro. Somente a disseminação do dano causal tem uma influência sobre a forma das contrações. Mas, além disso, conhecemos formas brandas nas quais tanto as manifestações das contrações, quanto o desmaio que as acompanha podem ser enfraquecidos ou mesmo desaparecer; e, finalmente, as moções pulsionais e os estados confusionais que se ligam às contrações ou as substituem. Estes últimos, apesar de determinadas variantes, têm semelhança com as formas de manifestação histéricas deflagradas pelas emoções, enquanto as moções pulsionais características da epilepsia procursiva e rotatória podem lembrar-nos dos distúrbios catatônicos. A maior variedade de manifestações patológicas encontra-se principalmente na epilepsia genuína. Somos forçados, portanto, a supor que esta mudança nas formas de manifestação depende de o ataque isolado da doença intervir mais ou menos profundamente no mecanismo da construção psíquica. Os amuos e as irritações, o desmaio passageiro e os estados inconscientes mantêm-se nos mesmos moldes daqueles transtornos que também podem ser causados por influências afetivas, enquanto os espasmos encontram sua origem em áreas que só excepcionalmente - na epilepsia afetiva e na epilepsia habitual dos alcoólatras - estão expostas a esse tipo de influências. Entre as duas formas situam-se as ações pulsionais, mesmo que de modo algum elas poderiam pertencer à mesma linha de desenvolvimento. Nas demais formas de epilepsia, as manifestações das contrações costumam ser dominantes, mas justamente na demência precoce e ocasionalmente também no estupor elas encontram uma ligação com transtornos esquizofrênicos e emocionais. Digna de nota é a frequência das manifestações das contrações na infância; nela, os dispositivos correspondentes parecem estar mais acessíveis e disponíveis do que depois do amadurecimento das áreas cerebrais que servem à manifestação da vontade superior.

As considerações aqui apresentadas têm uma longa história. Elas se atrelam à representação criada por von Guislain de que as diferentes fases de evolução dos transtornos mentais estão ligadas à disseminação gradativa dos processos patológicos sobre cada vez mais partes do cérebro. Schüle também desenvolveu pensamentos semelhantes ao fazer a distinção entre "psiconeuroses" e "psicoses cerebrais": nas primeiras, o sofrimento se manteria no âmbito dos transtornos funcionais e nas últimas, passaria para o âmbito orgânico. Wernicke, então, conside- 
rou a localização e a disseminação dos processos patológicos, em oposição às influências causais, como efetivamente determinantes para a formação dos quadros clínicos. De qualquer maneira, o ponto de vista de que as formas de manifestação de insanidade são determinadas essencialmente pela ação simultânea de disposições oriundas do histórico genético e da gênese pessoal é adequado para nos oferecer uma explicação para o intrigante fato de que, por um lado, ressurgem os mesmos transtornos em patologias totalmente diferentes e, por outro, de que os quadros clínicos, no transcorrer de uma mesma patologia, podem estar submetidos a muitas variações. Podemos comparar as manifestações patológicas com um órgão, cujos diferentes registros são colocados em funcionamento de acordo com a força ou a extensão das mudanças patológicas para, então, dar às manifestações do sofrimento o seu colorido particular, totalmente independente do tipo de influência que deu início a sua música. Os transtornos assim surgidos, portanto, não podem ser característicos de um determinado processo - no máximo na medida em que, de acordo com a experiência, este processo costumasse privilegiar ou limitarse a este ou àquele registro. Se apesar de todas as dificuldades de fato conseguimos reconhecer com bastante frequência o tipo de processo patológico a partir das formas de manifestação -, então esta experiência só fala a favor de que, de maneira geral, o mesmo sofrimento afeta os mesmos campos da mesma maneira e na mesma extensão.

Olhemos para trás mais uma vez e constataremos que conseguimos diferenciar ao menos três grupos principais de formas de expressão e de descrição da insanidade. O primeiro grupo é constituído pelas formas delirantes, paranoides, emocionais, histéricas e pulsionais; o último, pelas formas encefalopáticas, oligofrênicas e espasmódicas, enquanto no meio se encontra a forma esquizofrênica e talvez também a forma da fala alucinatória. Se nossos pontos de vista forem corretos, poderemos então esperar que os transtornos menos radicais do primeiro grupo de um modo geral se ligassem entre si ou, então, no máximo com os transtornos do segundo, mas nunca com os transtornos do terceiro grupo - enquanto as formas de manifestação desses dois últimos grupos frequentemente ou regularmente também são acompanhadas daquelas formas de manifestação do primeiro grupo. Por fim, no segundo grupo poderemos esperar de vez em quando misturas oriundas do primeiro bem como do terceiro grupo.

De fato constatamos a ausência de sinais de patologias cerebrais mais profundas nas patologias que se movimentam dentro das primeiras formas de manifestação mencionadas, enquanto, pelo contrário, os padecimentos inerentes ao terceiro grupo são frequentemente acompanhados de transtornos da primeira espécie - e a esquizofrenia, neste sentido, posiciona-se no meio, com suas manifestações delirantes, paranoides, emocionais, histéricas e pulsionais, de um lado, e, por outro, 
com seus ataques de contrações, seus movimentos rítmicos e sua confusão na fala. Certamente alguns processos patológicos também podem meramente situar-se no terceiro grupo de transtornos, sem afetar os desempenhos superiores - a não ser pelo déficit.

O ponto de vista de que uma parte não insignificante das manifestações patológicas provém do jogo autônomo de disposições pré-formadas de nossa personalidade corporal e psíquica parece-me especialmente fecundo para a compreensão dos transtornos epilépticos e histéricos. Inúmeros foram os esforços para delimitar e distinguir estas duas patologias totalmente diferentes em sua essência, com base nas manifestações clínicas. Estes esforços levaram a um aborto do conceito da histero-epilepsia e tiveram que falhar porque não foi possível encontrar marcas distintivas eficientes e validáveis para o sintoma aparentemente mais importante: os ataques. Se aceitarmos que os tipos de ataques não nos fornecem, por si mesmos, uma explicação segura sobre a essência da patologia, mas apenas assinalam a área de nosso mecanismo nervoso, na qual as patologias se desenrolam, então ficará compreensível que em ambas as patologias podem surgir concomitantemente manifestações epilépticas e histéricas. Nesse caso, a decisão sobre a essência de um processo patológico observado necessita então ser obtida, de preferência e provisoriamente, a partir do quadro psíquico geral; certamente outros pontos de apoio poderão ser considerados, especialmente as causas, talvez também o comportamento do metabolismo e muitas outras variações mais próximas dos processos patológicos que servem de base. É preciso ainda fazer apenas uma alusão ao fato de que, através das considerações que tecemos acima, fica livre o caminho para a delimitação destes transtornos epilépticos e histéricos que aparecem como sintomas concomitantes de doenças completamente diferentes.

Por um caminho semelhante talvez também seja possível diminuir as dificuldades que continuam a se colocar contra uma diferenciação confiável entre a doença maníaco-depressiva e a demência precoce. Nenhum entendido pretenderá negar que, infelizmente, são muitos os casos nos quais parece impossível chegar a um diagnóstico seguro, apesar da mais cuidadosa observação. A experiência de que não será possível limitar decisivamente o número de diagnósticos falhos tem um reflexo paralisante no entusiasmo do trabalho clínico e, com certeza, é uma das principais causas da disseminação da visão de que será infrutífero dar sequência aos esforços até hoje despendidos. Mesmo que eu acredite que estas queixas sejam apenas parcialmente pertinentes e que ainda será possível conseguirmos alcançar vários progressos por meio do aprofundamento da pesquisa e do incremento de nossos recursos até hoje bastante insuficientes, a impossibilidade cada vez mais evidente de conduzir satisfatoriamente a delimitação entre as duas patologias acima mencionadas deverá levantar com uma força cada vez maior a suspeita de que a 
nossa maneira de colocar a questão seja falha. Acredito que será necessário concentrarmo-nos na diferença básica entre os processos patológicos. A imensa massa - composta, de um lado, dos pacientes que se imbecilizam sem salvação ou apresentam severas destruições do córtex cerebral e, de outro, dos pacientes que sempre conseguem retomar as rédeas de sua personalidade - fala uma linguagem eloquente demais para que aceitemos a existência de transições reais, uma vez que com muita frequência é possível prever essa evolução a partir dos sintomas da doença.

Por outro lado, temos que considerar seriamente a questão de até onde os sinais - sobre os quais costumamos basear nosso julgamento - realmente nos conduzem a um aprofundamento na essência do processo patológico que nos é dado. Temos que admitir que, na maioria das vezes, isto é correto. Mas aparentemente sempre existe um campo ainda assim bastante amplo, sobre o qual tais sinais falham, seja por não estarem expressos de modo uniforme, seja porque não se mostram suficientemente confiáveis. Essa experiência se tornará bastante compreensível se partirmos do princípio de que a forma de manifestação emocional e esquizofrênica de insanidade não representa em si a expressão de determinados processos patológicos, mas literalmente indica os campos de nossa personalidade nos quais estes se manifestam. Seu significado característico residiria então apenas no fato de que as doenças esquizofrênicas normalmente atacariam partes de nosso mecanismo interno, diferentes da doença maníaco-depressiva. Mas quando a histeria oportunamente se alastra para as formas de manifestação epilépticas e, não raro, surgem transtornos histéricos nos epilépticos, então é de se pensar que estas duas patologias também saiam do enquadre das manifestações patológicas que lhes cabem habitualmente.

Constitui-se em uma experiência cotidiana o fato de que, nas patologias de ordem indubitavelmente esquizofrênica, surjam temporariamente - e às vezes por um tempo mais longo - quadros maníacos e melancólicos que simplesmente não conseguimos distinguir das formas circulares. Muito menos frequente, de qualquer maneira, é o desenvolvimento de sintomas claramente esquizofrênicos no transtorno maníaco-depressivo. Acharemos isto compreensível se ponderarmos que um processo patológico destrutivo também pode, paralelamente, ter efeitos inibidores ou excitantes de todos os tipos, enquanto um transtorno totalmente compensatório só excepcionalmente atuará com mais profundidade no mecanismo psíquico. $\mathrm{E}$ ainda é preciso ter presente que o significado característico dos transtornos esquizofrênicos é bastante diferente, mesmo que prescindamos da possibilidade de confusão com sintomas parecidos, mas de outra espécie. Do automatismo dos comandos, os degraus de uma escada conduzem à estereotipia e ao negativismo, passando antes pelo maneirismo e pela impulsividade, sobre os quais a essência 
esquizofrênica do sofrimento pode ser reconhecida com uma clareza cada vez maior. No entanto, nenhum destes sintomas - e nem mesmo a junção de todos eles - nos autoriza a concluir com absoluta certeza sobre a espécie de processo patológico que está em sua base. A comprovação mais evidente disso nos é oferecida pelo estupor. Mas também em muitas outras formas de insanidade, sobretudo nas patologias infecciosas e traumáticas, bem como nas encefálicas, deparamo-nos ocasionalmente com sintomas isolados ou combinados que de modo algum conseguimos distinguir daqueles referentes à esquizofrenia. Determinadas psicoses singulares, de evolução fatal rápida, típicas do período de involução, caracterizamse exatamente pela mistura de transtornos de angústia, melancolia e catatonia. Há pouco tempo ainda tive a oportunidade de acompanhar um caso de tétano que se instalou após a retirada de uma papeira de bócio, com evolução fatal, no qual se desenvolveram, um após outro, quadros patológicos de cunho totalmente maníaco e catatônico.

Portanto, precisaremos nos acostumar com o pensamento de que os sintomas patológicos por nós apreciados até aqui não são suficientes para nos oferecer, em todas as circunstâncias, uma distinção confiável entre o transtorno maníaco-depressivo e a esquizofrenia - e com o pensamento de que, nesse campo, sistematicamente, ocorrem interferências atribuíveis à origem dos sintomas patológicos, a partir de pré-condições já dadas. Não saberíamos dizer se as disposições gerais da personalidade humana são determinantes e, nesse caso, também a disseminação das mudanças patológicas - ou se as características herdadas tornam determinadas áreas mais vulneráveis ou mais expostas aos estímulos patogênicos. Se esta compreensão estiver correta, teríamos que procurar outros caminhos em casos difíceis a fim de obtermos maior clareza. Se nos ativermos ao exemplo acima discutido de epilepsia e histeria, ficaria em aberto, em primeiro lugar, o acompanhamento da evolução e do desfecho, bem como a avaliação da personalidade total do paciente; e, além disso, também as circunstâncias causais, que deveriam concentrar-se essencialmente em uma pesquisa das relações hereditárias. Não há dúvida de que esses caminhos são trilháveis e podem nos levar adiante. Não sabemos, no entanto, que dificuldades teriam que ser superadas, nem onde se encontram os limites do progresso. Naquelas doenças citadas em primeiro lugar, haveria a perspectiva justificada de que a pesquisa de suas bases corporais nos poderiam fornecer maiores esclarecimentos - tanto em vida, como após a morte; e, se essa esperança existe também para o distúrbio maníaco-depressivo e a demência precoce, só o futuro nos dirá.

O retrato que aqui conseguimos esboçar acerca da história do surgimento das manifestações patológicas certamente é bastante cru e incompleto. A construção histórico-genética da personalidade humana deu-se através de uma evolução mui- 
tíssimo lenta, de inúmeros progressos sutis, quase imperceptíveis; retrocessos também devem ter ocorrido; caminhos secundários devem ter sido trilhados e depois abandonados. O resultado final desse desenvolvimento interminável, em conformidade com a natureza, contém traços e resquícios dos mais diversos períodos da história genealógica, mesmo que a grande maioria das disposições inicialmente formadas e depois superadas tenha sido totalmente perdida. Por isso é que quando hoje tentamos relacionar as formas de manifestação de insanidade com os patamares isolados de desenvolvimento da personalidade, faltam-nos todos os pressupostos. Se estas experiências devem ir além de um tatear inseguro, será necessário ir atrás dessas manifestações de nossa vida interior em suas raízes - na psique da criança, do homem primitivo e dos animais - e, além disso, será necessário comprovar em que medida, nos estados patológicos, as moções perdidas da pré-história do desenvolvimento pessoal e genético-histórico ganham nova vida. Parece-me que as perspectivas que este tipo de reflexão oferece são bastante promissoras, apesar da pobreza de nosso conhecimento atual: elas poderiam contribuir para facilitar nossa tão difícil missão da compreensão clínica das formas de doença.

EMil Kraepelin (1856-1926)

Psiquiatra alemão, comumente citado como o criador da moderna psiquiatria, catedrático de Psiquiatria nas Universidades de Heidelberg e Munique. Autor do Tratado de Psiquiatria. 